\section{A 48,XYYY Male: A Somatic and Psychiatric Description}

\author{
Summary. Aspects of the physical, \\ dermatological, intellectual and person- \\ ality characteristics of an adult male of \\ 48,XYYY genotype are described. With \\ the exception of sterility no gross physical \\ or dermatographical abnormalities were \\ found. Diminished intellectual func- \\ tioning and abnormal personality traits \\ similar to those seen in males with other \\ sex chromosome abnormalities were ob- \\ served. Some possible origins of this \\ aneuploidy are discussed.
}

Chromatin positive sex chromosome abnormalities (47,XXY and its variants) have been frequently described with an incidence of 1.96 per 1000 in newborn males (Maclean et al, 1964). Chromatin negative $47, \mathrm{XYY}$ males are not so frequent, with an estimated incidence of 1.5 per 1000 live male births (Pitcher, 1971). Male pseudohermaphrodites have been described with $\mathrm{XX} / \mathrm{XXY} /$ XXYYY sex chromosomes (Fraccaro et al, 1962) and with 45,X/48,XYYY mosaicism (Cox and Berry, 1967). A male child aged 5 years with 48,XYYY genotype was described by Townes, Ziegler, and Lenhard (1965). This report concerns an adult male with $48, \mathrm{XYYY}$ genotype and is thought to be the first such adult described.

\section{Methods}

The man was discovered during a survey of all males $180 \mathrm{~cm}$ and over in height in hospitals for the mentally handicapped within the Sheffield Regional Hospital Board area.

Leucocytes were cultured using a modification of the method of Moorhead et al (1960). Analysis revealed that of 80 cells counted, 72 cells had 48 chromosomes, two had 47, four had 46, one had 45, and one had 49.

The constitution of the cells with 48 chromosomes is thought to be 48,XYYY. The extra chromosomes were $\mathrm{Y}$ chromosomes since they had the following features in

Received 26 June 1972. common: the long arms of the chromatids usually remained parallel throughout their length, they never participated in satellite association, and nearly always appeared on or around the periphery of the metaphase spread. There is absence of clinical signs attributable to aneuploidy of other $\mathrm{G}$ group members.

Fluorescent microscopy of buccal smear preparations showed three fluorescent spots in $24 \%$ of nuclei. In leucocyte metaphase cultures three chromosomes showed typical bright fluorescence on the distal half of their long arms characteristic of $\mathrm{Y}$ chromosomes (Fig. 1).

All cells with less than 48 chromosomes were analysed and all contained three $\mathrm{Y}$ chromosomes; there was, however, evidence in all these cells of random chromosome loss presumed to be from cell breakage. The one cell with 49 chromosomes was considered to be complete and revealed the presence of four $\mathrm{Y}$ chromosomes. Cytogenetic examination of the propositus' family was not possible except for one brother who was found to be normal.

\section{Case Report}

J.C. was born in 1920 , the eldest of four children. His parents are deceased and the parental ages at his birth could not be ascertained. The father's height is said to have been about $165 \mathrm{~cm}$, the mother's $183 \mathrm{~cm}$; his brothers are $170 \mathrm{~cm}$ and $183 \mathrm{~cm}$ and the sister $170 \mathrm{~cm}$. No physical abnormalities or histories of antisocial behaviour have occurred in the rest of the family.

No birth history is available. From the age of 5 to 10 years he attended elementary school where he was always bottom of the class. From the age of 10 years he has been resident in institutions for the mentally handicapped.

He is described by a brother as being taller and thinner than most other children, although he ate continuously. He has always been good at football, cricket and throwing balls and could run better than others.

Despite his advantages at sport, he was always 'odd man out', shouting, and prone to swearing. In a fight he would submit quickly and needed protection of a younger brother. At 10 years of age he was easily led and persistently pilfered, giving the pilfered money and goods to the customers of his father's public house. It was persistence of this type of behaviour that led to his admission to hospital.

His hospital files over the next 40 years have not proved useful in this investigation.

Nursing staff who have known him for over 20 years describe him as friendless, feckless, garrulous, loud voiced, boastful, argumentative, but conforming when disciplined. 


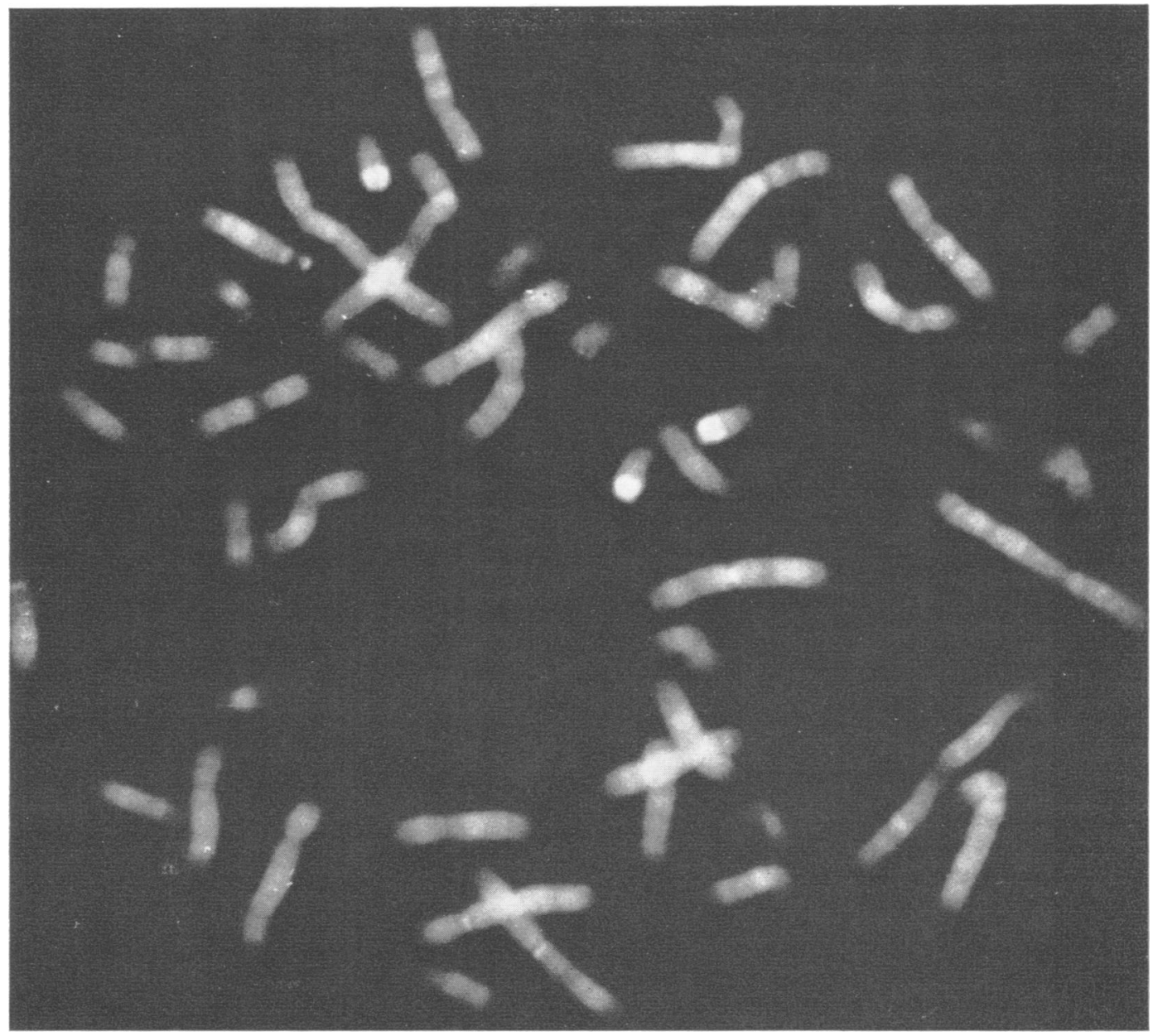

FIG. 1. Fluorescing metaphase spread showing three $\mathbf{Y}$ chromosomes.

$\mathrm{He}$ is lean and wiry in build, with large and powerful hands, and nurses describe him as being stronger than similar mentally handicapped patients. He weighs $66.7 \mathrm{~kg}$, and is $180 \mathrm{~cm}$ tall with span of $188 \mathrm{~cm}$, biacromial distance $47 \mathrm{~cm}$ and sole-pubic length $90 \mathrm{~cm}$. His head is somewhat elongated and flat with marked supraorbital ridges and a prognathic lower jaw. His hard palate is slightly raised and he is edentulous. The fifth toes of both feet are deformed, being at right angles to the others and crossing over the fourth; this deformity is not seen in other members of his family. His respiratory, cardiovascular, and central nervous systems show no obvious abnormalities and the EEG is within normal limits. He has bilateral varicose veins and also a right internal strabismus.

The right testis measures $2.5 \mathrm{~cm} \times 1.3 \mathrm{~cm}$; the left is similar but has an epididymal cyst. Sensation appears diminished in both testes. No spermatozoa were observed in two separate semen analyses.

Results of other investigations showed plasma testosterone to be $1.64 \mathrm{mg} / 100 \mathrm{ml}$; pituitary gonadotrophins $8.7 \mathrm{cu} / 24 \mathrm{hr} ; 17$-ketosteroids $6.2 \mathrm{mg} / 24 \mathrm{hr}$; $17-$ hydroxycorticosteroids $8.8 \mathrm{mg} / 24 \mathrm{hr}$.

Urine chromatography showed a normal pattern of amino acids.

Development of his physical secondary sex characteristics was delayed. Psychosexual development is difficult to assess because of his many years of residence in a completely male environment. Some three years ago, mixing of the sexes in supervised social activities was initiated. J.C. has tended to over-react to this innovation and attempts to pinch, cuddle, or kiss any female patient or staff who comes near him. This behaviour pattern has existed long after similar excitement has left 
his fellow patients and continues despite frequent remonstrations. Such activity is not judged to be attention seeking, nor is it attended by any obvious affect.

Intellectually his IQ has been assessed as 65 (WAIS full scale; verbal 63 and performance 72). This is in accordance with the child described by Townes et al (1965), whose IQ was 80. Both cases show reduction of intellectual function into the mild/moderate handicap range.

\section{Dermatoglyphic Findings}

Dermatoglyphics were obtained using the Faurot inkless method. Examination showed finger patterns of nine ulnar loops and one tented arch, with a total ridge count of 83 . The $a-b$ ridge count is 75 for both hands and the maximal atd angles of each hand is $40^{\circ}$. The dermatoglyphics showed little abnormality except for some disarrangement of ridges in the thumb of the left hand and second finger of the right hand, and on the hypothenar area of the left palm.

\section{Discussion}

This is the second 48,XYYY case reported and was found during a survey which has so far included over 1000 mentally handicapped males, suggesting a very low incidence.

The behavioural and personality characteristics of this man are reminiscent of the behaviour patterns and poor emotional responses seen in Klinefelter's syndrome (Hunter, 1969), with feckless behaviour, easy frustration, acting out verbally rather than physically, and towards property rather than persons. Although bullying in manner and voice, when faced with firmness he soon submits. Although physically strong, his submission to firm handling may reflect some fundamental characteristic, for it was noticed by his family from a very early age. It is of interest to note the raised performance/verbal IQ ratio which is also seen in other sex chromosome disorders in males and in psychopathic behaviour disorders.

The triple $\mathrm{Y}$ condition appears compatible with a reasonable life span and this is in agreement with the proposition that the $\mathrm{Y}$ chromosome contains little important genetic material other than that responsible for testicular formation (Bartalos and Baramki, 1967). Two supernumerary $Y$ chromosomes are apparently attended by sterility.

The dermatoglyphic findings show that the total ridge count and $\mathrm{a}-\mathrm{b}$ ridge count is lower than that for normal males and those with an extra $Y$ chromosome. This complies with the expected pattern that the more complex the sex chromosome aneuploidy the simpler the finger pattern (Hunter, 1968).

An XYYY genotype might arise from the fertilization of a normal ovum by a YYY sperm. A sperm containing three $\mathrm{Y}$ chromosomes could theoretically be produced by secondary nondisjunction or anaphase lagging in meiosis II from an XYY primary spermatocyte. The father of our propositus may have been genotypically $47, \mathrm{XYY}$ but this is considered unlikely as he presented none of the phenotypic characteristics usually associated with the possession of a supernumerary $\mathrm{Y}$ chromosome. There is, however, the possibility that his testicular tissue alone was $47, \mathrm{XYY}$.

Recurrent nondisjunction of the $\mathrm{Y}$ chromosome in a normal zygote might be expected to produce a mosaic of at least three cell lines, $\mathrm{X}, \mathrm{XY}$, and $\mathrm{XYYY}$. A familial tendency to nondisjunction has been described (Hauschka et al, 1962). In our case no evidence to support either a mosaic in the chromosome analysis of the propositus or clinical abnormalities in his family were detected.

Normal donors have been observed to produce $1.26 \%$ of YY sperms (Sumner, Robinson, and Evans, 1971). Nondisjunction or anaphase lagging in a zygote so formed might be expected to produce a mosaic of 46,XY/48,XYYY cell lines. To reconcile this theoretical possibility with the actual findings would require that the cell line $48, X Y Y Y$ was selected.

This work was done as part of a larger research project financed by the Research Committee of the Sheffield Regional Hospital Board and with equipment donated by the National Association for Mental Health.

We should like to thank both Mrs N. Polani, Guy's Hospital, London, who kindly analysed and reported on the dermatoglyphic findings, and Dr M. Bobrow, MRC Population Genetics Unit, Oxford, who prepared and photographed the fluorescing metaphase spread.

We wish to express thanks to Dr J. W. Garry, Harmston Hall Hospital, who allowed us to examine his patient.

\section{HENRY HuNTER and Roger QUAIFE* \\ Balderton Hospital, Newark, Nottinghamshire}

REFBRENCES

Bartalos, M. and Baramki, T. A. (1967). Medical Cytogenetics. Williams and Wilkins, Baltimore.

Cox, D. and Berry, C. L. (1967). A patient with 45XO/48XYYY Mosaicism. Fournal of Medical Genetics, 4, 132-133.

Fraccaro, M., Taylor, A. I., Bodian, M., and Newns, G. H. (1962). A human intersex ('true hermaphrodite') with XX/XXY/XXYYY sex chromosomes. Cytogenetics, 1, 104-112.

Hauschka, T. S., Hasson, J. E., Goldstein, M. N., Koepf, G. F., and Sandberg, A. A. (1962). An XYY man with progeny indicating familial tendency to non-disjunction. American fournal of Human Genetics, 14, 22-30.

Hunter, H. (1968). Finger and palm prints in chromatin-positive males. Fournal of Medical Genetics, 5, 112-117.

* Present address: Area Medical Genetics Service, Department of Human Morphology, University of Nottingham Medical School. 
Hunter, H. (1969). A controlled study of the psychopathology and physical measurements of Klinefelter's syndrome. British fournal of Psychiatry, 115, 443-448.

Maclean, N., Harnden, D. G., Court Brown, W. M., Bond, J., and Mantle, D. J. (1964). Sex chromosome abnormalities in newborn babies. Lancet, 1, 286-290.

Moorhead, P. S., Nowell, P. C., Mellman, W. J., Battips, D. M., and Hungerford, D. A. (1960). Chromosone preparations of leukocytes cultured from human peripheral blood. Experimental Cell Research, 20, 613-616.

Pitcher, D. R. (1971). The XYY syndrome. British fournal of Hospital Medicine, 5, 379-393.

Sumner, A. T., Robinson, J., A., and Evans, H. J. (1971). Distinguishing between $\mathrm{X}, \mathrm{Y}$ and $\mathrm{YY}$-bearing human spermatozoa by fluorescence and DNA content. Nature New Biology, 229, 231-233.

Townes, P, L., Ziegler, N., A. and Lenhard, L. W. (1965). A patient with 48 chromosomes (XYYY). Lancet, 1, 1041-1043.

\section{Deletion from the Long Arm of Chromosome 4 (46,XX,4q-) Associated with Congenital Anomalies*}

Summary. A congenitally malformed infant with a partial deletion of the long arm of chromosome 4 identified by Giemsa banding studies is described. The relationship of the anomalies to the chromosome abnormality is discussed.

Although a number of chromosome deletion syndromes involving the $B$ group have been described, only the cri-du-chat syndrome $(5 p-)$ and Wolf syndrome $(4 p-)$ have been reported often enough for an associated constellation of anomalies to be delineated (Guthrie et al, 1971; Hamerton, 1971). We wish to describe a congenitally malformed infant with a partial deletion of the long arm of chromosome 4 identified by Giemsa banding studies. Case reports involving a ring 4 chromosome have been published (Carter, Baker, and Hayman, 1969; Dallaire, 1969; Faed, Stewart, and Keay, 1969; Hecht, 1969; Surana, Bailey, and Conen, 1971) but only one previous report describes a deletion from only the long arm $(4 q-)$ (Ockey et al, 1967). Chromosome identification in these cases was by morphology or autoradiography.

\footnotetext{
Received 31 July 1972 .

* Requests for reprints to Mitchell S. Golbus, MD, Department of Pediatrics, University of California-San Francisco, California 94122, USA.
}

\section{Case Report}

K.R., a black female, is the first child of a 22 -year-old mother and 21-year-old father. She weighed $3360 \mathrm{~g}$ at birth and was born at term by a spontaneous vaginal delivery. There was no family history of congenital malformations or mental retardation, and the parents were not related. No drugs were ingested during the early part of pregnancy and there were no prenatal infections. However, the gestation was complicated by peripheral oedema in the eighth month treated with a two-week course of diuretics. The patient was referred to the University of California Medical Center at 4 weeks of age for failure to thrive, recurrent regurgitation, and tachypnoea without cyanosis while feeding.

Positive physical findings included a prominent occiput, superiorly pointed (elfin) ears with incomplete helices, a shortened nasal septum causing an upturned nose, a midline cleft of the palate, a bifid uvula, mild micrognathia, pour oropharyngeal muscular tone in contrast to good generalized tone, a grade III/VI harsh systolic murmur, an accentuated pulmonic second heart sound, an enlarged liver, a $1 \mathrm{~cm}$ umbilical hernia, a $1 \mathrm{~cm}$ café-au-lait spot in the right lower quadrant of the abdomen, a sacral dimple, a short distal phalanx of the left fifth finger with an absent extensor crease, and bilateral plantar displacement of the third toes (see Fig. 1).

Dermatoglyphics revealed seven ulnar loops, two whorls, and one radial loop with both palms having a single axial triradius (atd angle $=25^{\circ}$ ). A hallucal arch pattern was present bilaterally.

An intravenous pyelogram showed a duplicated left intrarenal collecting system. Cardiac catheterization with angiograms revealed pulmonary hypertension, an enlarged right atrium and ventricle, a small atrial septal defect (ASD) with left-to-right shunting, and inadequate alveolar ventilation. No cause for the last finding other than the relative macroglossia, increased pharyngeal secretions, and poor oropharynx muscle control was found. For the same reasons poor feeding was a continuing problem.

An endotracheal tube improved ventilation and at 6

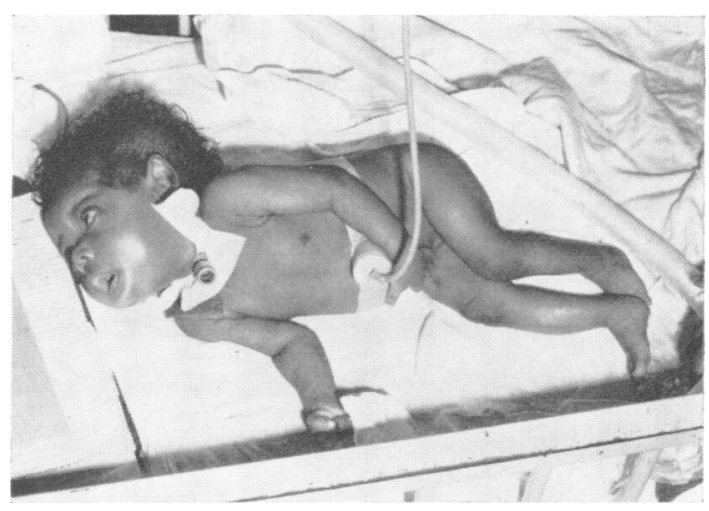

Fig. 1. The proposita at one month of age. 